\title{
LA CONSTRUCCIÓN SOCIAL DEL MERCADO DE LA SOJA EN PARAGUAY ${ }^{1}$
}

THE SOCIAL CONSTRUCTION OF THE SOYBEAN MARKET IN PARAGUAY

Valdemar João Wesz Junior ${ }^{2}$

Enviado: 6/8/2020

Aceptado: 2/2/2021

Resumen: En la literatura y en el imaginario social, el mercado de la soja aparece, de manera predominante, como un intercambio impersonal, basado en una racionalidad económica desprovista de convivencia y relaciones sociales. En una dirección opuesta, este artículo analiza la construcción social del mercado local de la soja en Paraguay, enfocándose en la relación establecida entre productores rurales y empresas. Además del uso de una literatura

${ }^{1}$ Una discusión inicial en este tema fue realizada en la región Sudeste de Mato Grosso, Brasil (Wesz Jr., 2014 y 2019).

${ }^{2}$ Universidad Federal de la Integración Latinoamericana (UNILA) - Brasil.

Contacto: valdemar.junior@unila.edu.br 
académica especializada, datos secundarios e información disponible en medios de comunicación, fue realizada una profunda investigación de campo en Paraguay, entre 2014 y 2020. Este artículo concluye que el precio y las condiciones del contrato son factores importantes en este mercado, pero la negociación entre productores y empresa está construida y sostenida por un conjunto de otros elementos arraigados en la vida social y comunitaria.

Palabras clave: mercado de la soja; relación comercial; sociología económica; Paraguay.

Abstract: In literature and in the social imaginary, the soy market appears, predominantly, as an impersonal exchange, based on an economic rationality devoid of coexistence and social relations. In an opposite direction, this article analyzes the social construction of the local soybean market in Paraguay, focusing on the relationship established between farmers and companies. In addition to the use of specialized academic literature, secondary data, and information available in the media, in-depth field research conducted in Paraguay between 2014 and 2020. This article concludes that the price and conditions of the contract are important factors in this market, but the negotiation between farmers and companies is constructed and sustained by a set of other elements rooted in social and community life.

Keywords: soybean market; business relationship; economic sociology; Paraguay. 


\section{Introducción}

Cuando se piensa en el mercado de la soja, vienen en mente relaciones formales e impersonales, ajenas a las dinámicas sociales y comunitarias, ya que se trata de una actividad estandarizada, con precio establecido internacionalmente $y$ pautado en un comercio global. Y, en el caso de Paraguay, se suma a esto la predominancia de una producción en gran escala, controlada por productores extranjeros y por empresas transnacionales (Rojas Villagra, 2009; Galeano, 2012; Wesz Jr., 2018 y 2021). Esta representación se torna aún más fuerte en los discursos de empresas, productores y gremios de la cadena, que enfatizan temas como gestión empresarial, padrón tecnológico, crecimiento de la producción y de la productividad, que, por un lado, sobrestiman el discurso de la eficiencia económica, y por otro, 107 excluyen un conjunto de situaciones sociales que allí están (Heredia, Palmeira y Leite, 2010). En función de esto, existe la idea de que el mercado de la soja es ajeno a los aspectos sociales, culturales e históricos, como si se tratara de externalidades que no interfieren en la relación y no poseen poder explicativo, una vez que la lógica productiva, comercial $y$ financiera es predominante.

Sin embargo, ¿el mercado de la soja es inmune a las variables sociales? ¿Cuál es el peso de las dimensiones no económicas en este mercado? Para responder estas preguntas, se podrían mirar diferentes momentos de la cadena productiva o tener distintas escalas de análisis, como hicieron: Busch y Tanaka (1996), que explican cómo se construye un determinado standard de una commodity global, argumentando que una norma técnica es resultado de un largo proceso de negociación de valores entre diferentes 
actores; Wilkinson (2011), que argumenta cómo la actuación de organizaciones de la sociedad civil y movimientos sociales son clave en la construcción de nuevas reglas en la certificación de productos alimentarios (como la "soja responsable"); Desconsi (2017), apunta que la producción de soja por asentados de la reforma agraria en Brasil está vinculada a una pluralidad de nexos sociales, que incluyen tanto relaciones personales, de parentesco y vecinales, al mismo tiempo que está configurada por diferentes tipos de autoridad, redes y por múltiples identidades.

En este artículo, a partir de la Nueva Sociología Económica, vamos a analizar la construcción social del mercado local de la soja en Paraguay, enfocándonos específicamente en la relación que los productores rurales establecen con las compañías para comprar insumos y vender su cosecha. En este sentido, procuraremos mostrar cómo ocurre la interacción entre dos actores claves del mercado de la soja (agricultores y empresas) y qué elementos/condiciones son importantes en el momento de decidir con quién negociar. Es importante decir que este es un vínculo central para ambos, pues puede definir el éxito o el fracaso de una zafra.

Además del uso de una literatura académica especializada, este artículo utiliza datos secundarios, y se recopiló información en los medios de comunicación. No obstante, las principales fuentes son las investigaciones de campo realizadas entre 2014 y 2020 en Paraguay, donde se realizaron 182 entrevistas semiestructuradas con diferentes actores de la cadena de producción, como productores de soja, industrias de agroquímicos, semillas y fertilizantes, revendedores de insumos, cooperativas, silos, exportadores y asociaciones comerciales, además de autoridades públicas e investigadores del tema. Entre las empresas, fueron 
entrevistadas las principales compañías que trabajan con oferta de insumos o compra de soja en Paraguay, como Cargill, ADM, Dreyfus, Cofco, Agrofértil, Agrotec, Diagro, Matrisoja, Agrícola Colonial, Dekalpar, Ciabay, Glymax, Tecnomyl, Seagri, Agro Silo Santa Catalina (Grupo Favero), Sul América Insumos, Lar, Syngenta, entre otras.

Entre los productores de soja, fueron entrevistados 107 en total, los cuales presentaron una gran diversidad en términos de: orígenes (brasileño, paraguayo, alemán, menonita, americano y argentino); tamaño (desde 2,0 hasta 22 mil hectáreas de soja sembrada); tiempo en la actividad en el país (de 45 hasta 2 años); localidades en que produce soja (Departamento de Alto Paraná, Itapúa, Canindeyú, Caaguazú, Caazapá, Amambay, San Pedro y Boquerón); infraestructura (desde aquellos que tercerizan todo el proceso de producción hasta aquellos que tienen todas las máquinas y estructuras en la finca); y formas de negocio (venta al contado, intercambio de granos por insumos y préstamo en efectivo).

También fue realizada observación participante en las principales ferias agrícolas del país, como Expo Santa Rita 2015 y 2016 (en el distrito de Santa Rita - Alto Paraná), Innovar 2017 (en el distrito de Colonia Yguazú - Alto Paraná) y Expo Regional Canindeyú 2017 (en el distrito de La Paloma do Espírito Santo - Canindeyú). Una observación metodológica importante es que, cuando fueron reproducidas en el texto las conversaciones con los entrevistados, se mantuvo el idioma original de la charla. Se tomó esta decisión para no alterar ni interferir en la expresión original, sobre todo porque hay algunas palabras que no tienen traducción o que perderían su significado en otro idioma. También se optó por no identificar el responsable de cada declaración, pero 
distinguimos su principal rama de actuación (productor rural, distribuidora, acopiadora, exportador, etc.).

Este trabajo está estructurado en tres partes, además de esta Introducción y de las Consideraciones finales. Inicialmente, hay una breve presentación de la Nueva Sociología Económica, trayendo los principales argumentos y líneas de investigación. En la secuencia, el foco es el mercado local de la soja en Paraguay, presentando los actores involucrados y las modalidades de relacionamiento entre ellos. Por fin, se profundiza la construcción social del mercado a partir de las relaciones establecidas entre productores y empresas en Paraguay, analizando los elementos que estructuran, mantienen y solidifican las negociaciones entre ellos.

\section{Breve presentación de la Nueva Sociología Económica (NSE)}

El inicio de la Nueva Sociología Económica (NSE) es asociado, consensualmente, con los trabajos de Mark Granovetter en los años $1970^{3}$. Si bien las teorías económicas poco tienen en cuenta las estructuras y redes sociales en la definición del comportamiento económico, la NSE destaca precisamente que el proceso de producción, la formación de mercados y la gestión económica son expresiones de la interacción entre las personas, lo que promueve un arraigo o

\footnotetext{
${ }^{3}$ La denominación "Nueva" Sociología Económica ocurre porque hubo un primer movimiento de estudios en las décadas de 1890 a 1920, encabezado principalmente por Durkheim, Pareto y Weber, cuyo análisis sociológico mostró cómo la dimensión social influyó en los eventos económicos (Steiner, 2006; Raud-Mattedi, 2005).
} 
enraizamiento (embeddedness) de los mercados en la sociedad contemporánea ${ }^{4}$ (Granovetter, 1985).

La NSE critica los fundamentos más tradicionales de la teoría económica, que entiende el mercado como un punto de equilibrio entre la oferta y la demanda, alcanzado por la acción independiente, soberana, instrumental y atomizada de individuos que no tienen ningún tipo de relación permanente entre sí. Con base en estos supuestos, la NSE busca demostrar que el funcionamiento de la economía no puede explicarse simplemente por la gerencia mercantil (precios), señalando la necesidad de reintroducir "instituciones y diferentes formas de comportamiento social en el análisis, para dar cuenta de la articulación entre los actores del mercado" (Steiner, 2006). Al abrir la "caja negra" del mercado, lo que hay dentro son lazos sociales, interacciones, cuyos significados están siendo construidos, permanentemente, por las personas (Abramovay, 2006). Por lo tanto, la NSE rechaza la supuesta hostilidad bajo la cual la economía y la sociedad son representadas con tanta frecuencia. La sociología económica "surgió como una respuesta a la expulsión de la vida social del análisis económico, tanto en la visión neoclásica como en las formulaciones de la nueva economía institucional" (Wilkinson, 2008).

\footnotetext{
${ }^{4}$ La noción de embeddedness fue utilizada inicialmente por Polanyi ("La gran transformación") para mencionar que en las sociedades precapitalistas, las transacciones mercantiles tenían sus raíces en las relaciones sociales, ya que el entorno económico estaba organizado por las costumbres y las normas de la comunidad. Sin embargo, el autor argumenta que a medida que el mercado se autorregula, se vuelve autónomo de las estructuras sociales y la sociedad sufre un desarraigo de las acciones económicas (Polanyi, 1980). Sin embargo, Granovetter (1985) reformuló este concepto al mostrar que incluso en las sociedades contemporáneas, que están sujetas al orden mercantil, existe una inserción social relativa. Un ejemplo es el peso que la amistad y las relaciones familiares ejercen en procesos que, en apariencia, son puramente económicos.
} 
Por lo tanto, el mercado no puede ser tratado de manera sustancial, como un elemento auto explicativo, jerárquico e independiente, pues necesita ser trabajado en su dimensión procesal, en la cual los actores desarrollan estrategias, catalizan diferentes tipos de recursos y construyen relaciones interdependientes de otras dimensiones de la vida social. Por lo tanto, las acciones económicas se construyen a partir de la relación entre actores que se conocen, cooperan y compiten por posiciones, cuyas estrategias varían según los recursos disponibles, la posición de los agentes en el espacio social y su trayectoria histórica (Granovetter, 1985; Bourdieu, 2001; Fligstein, 2001; Zelizer, 2003; Steiner, 2006; entre otros).

Para Wanderley (2002) y Marques (2003), la NSE puede ser dividida, a partir de las diferentes orientaciones adoptadas, en tres enfoques principales: redes sociales, cognitivo/cultural y político-institucional. El primer enfoque resalta la importancia de las redes sociales en las acciones económicas, señalando

su influencia en el comportamiento de los actores, de las instituciones y, en consecuencia, del mercado. Granovetter (1985), el autor principal de esta línea de interpretación, argumenta que los mercados tienen sus raíces en las redes sociales, ya que facilitan la circulación de información y aseguran la confianza de los agentes al limitar los comportamientos oportunistas. El segundo enfoque, cognitivo/cultural, comprende la importancia de la cultura en la definición de los intercambios y las estrategias de los actores, así como la forma en que los comportamientos son apropiados o no por la esfera económica. Zelizer (2003), una de las principales investigadoras de esta perspectiva, señala que el mercado está definido por un conjunto de valores morales ubicados en una cultura determinada, de modo que las transacciones económicas están impregnadas de dimensiones éticas, religiosas, sentimentales, etc. El enfoque 
político-institucional, a su vez, destaca la participación del Estado y otras organizaciones en la formación de las reglas generales que estructuran las relaciones de mercado. Estas reglas, que pueden ser tanto leyes como significados colectivos, son responsables de proporcionar condiciones estables y seguras para que los agentes se organicen, compitan, cooperen y realicen transacciones. Fligstein (2001 y 2003) fue un interlocutor central en este enfoque de la NSE y una de sus principales contribuciones fue reconocer que el Estado y el mercado están estrechamente vinculados, al construir instituciones para controlar las acciones económicas, como los derechos de propiedad, reglas de intercambio, etc.

A pesar de estos diferentes enfoques, Jeans Beckert (2009 y 2010) propone romper esta segmentación de la NSE, al reconocer las interrelaciones entre redes sociales, instituciones y marcos cognitivos, además de defender la irreductibilidad de un elemento a otro. Beckert, para estructurar su plan de análisis, utiliza varios autores desde diferentes perspectivas de la NSE, como Granovetter, Callon, Fligstein, Zelizer, DiMaggio, Lawrence, Bourdieu y White.

Siguiendo la propuesta de Beckert (2009 y 2010), las redes sociales pueden definirse como estructuras de interacción regular que se basan en la confianza, la reciprocidad y la trayectoria de la relación, rompiendo con la interpretación de actores anónimos e impersonales. El autor enfatiza la importancia de las relaciones sociales para el desarrollo de las transacciones económicas, ya que la elección entre un contrato y otro, por ejemplo, puede variar de acuerdo con la trayectoria de las interacciones establecidas entre los actores, siendo la confianza una condición fundamental para que las negociaciones ocurran. El marco cognitivo reconoce 
la importancia de las creencias morales, religiosas, simbólicas, políticas, ideológicas e intelectuales, ya que estos valores indican las preferencias de los agentes y también definen la demanda del mercado. Estas percepciones y calificaciones se reflejarán en las elecciones de los actores, en el posicionamiento en ciertos contextos y en la definición de estrategias. Las instituciones son las reglas formales e informales establecidas por los actores del mercado, el Estado y los grupos de interés, cuyo objetivo es regular los límites, las capacidades, la configuración y las normas del mercado. Para reducir la incertidumbre de la transacción, construir instrumentos de protección y confirmar las expectativas, las reglas pueden materializarse en acuerdos, contratos, etc., que a menudo definen precios, formas de pago, etc. (Beckert, 2009 y 2010).

Este estudio, dentro de la NSE, adhiere a la propuesta de Beckert (2009 y 2010), que establece que los mercados son interferidos tanto por las instituciones como por los valores y relaciones sociales, dado que estos elementos son interdependientes y están interrelacionados. Y, cuando mencionamos la construcción social de los mercados, nos referimos a un proceso de interacción económica que es construido socialmente, que implica la intermediación de mercancías, pero extrapola los medios propiamente económicos. Aunque la mayoría de las conexiones establecidas tienen una motivación comercial, el intercambio nunca se limita solo a esa esfera, involucrando, al mismo tiempo, aspectos sociales, culturales, políticos e históricos. En este sentido, el mercado no es una esfera autónoma, sino que está impulsado por agentes que se insertan en la vida social y comunitaria (Granovetter, 1985; Bourdieu, 2001; Steiner, 2006). 
Antes de entrar en las relaciones entre productores de soja y empresas, es importante presentar las principales características de este mercado en Paraguay, pues es en este contexto que se construye la interacción entre los dos actores.

\section{El mercado de la soja en Paraguay: productores, empresas y relación comercial}

El mercado de la soja tiene diferentes actores, directa o indirectamente involucrados con la producción, como productores rurales, industrias de maquinaria, semillas, fertilizantes y agroquímicos, revendedores, bancos, empresas de asistencia técnica, acopiadoras, agroindustrias, transportadores, cooperativas, organizaciones gremiales 115 (que representan a productores y empresas), etc. No hay duda de que los productores rurales tienen gran importancia, pues son los responsables del cultivo del grano. En el último Censo Agropecuario de Paraguay (2008), existían 28.917 fincas con producción de soja en el país (un aumento de $8,2 \%$ en relación al Censo de 1991), distribuidos principalmente en los departamentos de Itapúa $(42,2 \%$ del total), Alto Paraná $(26,7 \%)$, Canindeyú $(10,5 \%)$, Caaguazú $(8,2 \%)$ y Caazapá (7,5\%), pero había cultivo en todos los departamentos orientales (MAG, 2009).

En Paraguay, los productores de soja presentan una gran diversidad de situaciones, en términos productivos, económicos, de nacionalidad y de área, tal como fue posible captar en la investigación de campo. En términos de número de explotaciones, son muy importantes las fincas que tienen hasta 20 hectáreas, que eran la mitad de los productores de 
soja en 2008. Sin embargo, este cultivo está cada vez más concentrado. Las unidades de más de mil hectáreas, que en 1991 totalizaron el 17\% del área sembrada, en 2008 alcanzaron prácticamente la mitad (MAG, 2009). Otra característica es la fuerte presencia de productores extranjeros, los que controlaban $64 \%$ de la soja en Paraguay en 2008 , de los cuales el $50 \%$ eran brasileños y el $14 \%$ eran de otros países sudamericanos (especialmente argentinos), europeos (principalmente alemanes y españoles) y asiáticos (predominantemente japoneses). Al cruzar la nacionalidad y el tamaño de la propiedad, es evidente que "son los productores extranjeros los que predominan en las medianas y grandes explotaciones. Por consiguiente, en la producción de este rubro agrícola, se confirma la correlación entre la concentración y la extranjerización" (Galeano, 2012).

En términos de las empresas, en las últimas dos décadas llegan al país las principales compañías transnacionales globales, motivadas, entre otras cosas, por el potencial de crecimiento de la producción de soja - que pasó de 3,0 para 11,0 millones de toneladas entre 1998/99 y 2017/18 (MAG, 2020). Estas empresas pasaron a tener un significativo poder de mercado en diferentes momentos de la cadena productiva. En el sector de maquinarias, $\mathrm{CNH}$ (con las marcas Case $\mathrm{IH}$ y New Holland), AGCO (con las marcas AGCO, Valtra y Massey Ferguson) y John Deere, controlaban el $94 \%$ del mercado de tractores y el $91 \%$ del mercado de cosechadoras, en 2018 (Cadam, 2019). En el segmento de semillas, en el mismo año, el $87 \%$ de este mercado está concentrado en ChemChina (que adquirió Syngenta y Nidera Seeds), Bayer (que compró Monsanto) y GDM Seeds (Aprosemp, 2018). En el comercio de agroquímicos, la situación cambió, pues era muy dependiente de Syngenta, Basf, DuPont, Dow, Bayer y Monsanto, pero actualmente muchas distribuidoras (como 
Agrotec, Agrofértil, Dekalpar, Diagro, Ciabay, Glymax, Matrisoja, Somax Agro, entre otras) empiezan a importar productos genéricos de China y también actúan con marcas propias. En el sector de fertilizantes, además de la presencia importante de algunas distribuidoras, en una estrategia de también importar el producto, son muy fuertes las empresas que actúan en el comercio de granos, como Cargill, Bunge, Dreyfus y Cofco (DNA, 2020).

En el comercio de la soja ${ }^{5}$ predominan las firmas transnacionales americanas ADM, Bunge y Cargill, además de la francesa Dreyfus, popularmente conocidas como ABCD (Murphy, Burch y Clapp, 2012; Wesz Jr., 2016). Y, más recientemente, entraron en el mercado la estatal china Cofco y la rusa Sodrugestvo. En el caso de la harina y aceite de soja, ABCD controlaba más del $85 \%$ de este segmento en 2019 (DNA, 2020). En el mercado de la soja in natura, la líder es Cofco, con el 19\% de las exportaciones, en 2019 , seguido por Sodrugestvo (17\%). Sumando con el poder de mercado de $A B C D$, las seis compañías controlan más del $70 \%$ de las exportaciones de soja en grano en Paraguay (Capeco, 2020).

Si en un primer momento estas empresas, con destaque a $A B C D$, actuaban directamente con los productores rurales, lo que se percibe en los últimos años es que esta conexión se hace, cada vez más, por distribuidoras de insumos (que ahora también tienen sus propios productos/marca, como se ha visto arriba), cooperativas y acopiadoras. Esta situación fue

\footnotetext{
${ }^{5}$ En Paraguay, el principal destino para la producción de soja es la exportación. Si sumamos la exportación total (in natura y procesada) en los últimos 20 años (entre $1999 / 00$ y $2018 / 19$ ), alcanza más del $92 \%$ de toda la producción del país, con el $64 \%$ exportado en grano y el $27 \%$ exportado de manera industrializada (como el aceite y el harina), quedando en Paraguay $3 \%$ para semillas y $5 \%$ para consumo interno (principalmente a través de harina) (Capeco, 2020).
} 
mencionada por diferentes entrevistados, que destacaban como principales motivaciones el alto costo de mantener toda la estructura (silos, balanza, funcionarios, etc.) y el hecho de que las empresas transnacionales tienen un conjunto de reglas, sobre todo de seguridad, lo que amplía aún más este costo, pero también tienen horarios más limitados, que impiden la recepción de la producción a cualquier hora, mientras que las empresas locales son más flexibles. Según lo dicho por el gerente de una acopiadora (Entrev. 2019), "a burocracia das multinacionais é a nossa sobrevivência". "A multinacional faz a regra e segue na risca: [o produtor] cumpriu o requisito, tem crédito; não cumpriu, não tem. Eles são mais quadrados nessa parte, enquanto as empresas locais têm mais flexibilidade, porque conhecem as pessoas com quem estão negociando" (Cooperativa, entrev. 2019).

Cargill, por ejemplo, tenía 37 silos en Paraguay en 2015, que eran sucursales donde ofrecían a los productores rurales los insumos y servicios para el cultivo de la soja y donde recibían y acopiaban el grano. Actualmente, el número está en 16 silos, que se quedaron en las principales zonas de producción y cercanas de su planta industrial de Minga Guazú, como Santa Rita, Santa Rosa del Monday, San Alberto, Los Cedrales, entre otros (Cargill Paraguay, 2020). Lo mismo ocurrió con otra exportadora transnacional, como comenta su gerente de Santa Rita:

Nós tínhamos 33 silos dentro do Paraguai, hoje temos 13. Porque tem regiões que estava sendo mais barato [comprar o grão de terceiro]. Sabe que hoje o custo de personal, o custo de mantenimento com o silo é um custo caro e em algumas regiões a empresa decidiu que era mais barato ela pagar 10 dólares a mais para 0 
cara com a soja limpo e seco do que manter um silo funcionando 365 dias por ano. Também tem a questão de que temos a fábrica e os nossos silos armazenam os nossos produtos para que a fábrica não pare determinadas épocas do ano que tem escassez de grão, por isso que não vamos terminar com os silos, só se vender a fábrica, [...] aí terceiriza, só compra daqui e entrega lá e tchau (Exportador, entrev. 2019).

Sodrugestvo, que no tiene industria en el país, desde que ingresó en Paraguay en 2014 "tem um escritório com 3 ou 4 pessoas e estão comprando volumes astronômicos" (Cooperativa, entrev. 2019). Aunque ABCD y Cofco no llegaron a esta situación, y mantienen solo los silos más rentables y estratégicos, está claro que están priorizando cada vez más la adquisición de soja vía oficinas comerciales, comprando el grano directamente de distribuidoras de insumos, cooperativas, acopiadoras y grandes productores, que en la mayoría de las veces entregan la soja directamente en el puerto o en su agroindustria. De esta manera, los productores de soja en Paraguay están realizando, cada vez más, sus negociaciones con distribuidoras de insumos, cooperativas y acopiadoras locales, y también en los silos que las exportadoras transnacionales siguen operando.

En Paraguay existen básicamente tres modalidades de negociación entre productores de soja y empresas. La primera, y menos recurrente, es la adquisición de los productos y servicios con pago en efectivo en el día de la compra. Esta opción es más frecuente entre grandes productores capitalizados, que tienen recursos y optan por este camino para obtener mejores precios. También la 
aprovechan algunos pocos productores medianos en la compra de algún insumo específico y de manera puntual, o que hicieron un préstamo en el banco para costear su producción. Sin embargo, lo que efectivamente predomina en el cultivo de la soja son otros dos tipos, o sea, contratos de financiamiento a corto plazo.

La segunda modalidad es el intercambio de productos y servicios (principalmente semillas, agroquímicos, fertilizantes y asistencia técnica, pero algunos también incluyen alquiler de tierra y máquinas, seguro y combustible) por granos. Como afirmó un técnico 6 , "nosotros somos un supermercado. Lo que el productor necesita, tenemos acá" (Distribuidora, entrev. 2017). Y, como señala un agricultor, "tomo lo que necesito para mi producción y en la zafra pago con soja" (Entrev. 2016). Esta modalidad es conocida como barter, en que el productor hace este "paquete" y paga su deuda en la zafra sin intermediación monetaria. Así, el costo es convertido en soja, cuyo precio puede ser del día de la firma del contrato (una venta anticipada, considerado un contrato futuro) o puede ser con el precio del día de entrega del grano. "Muitos antecipam o preço de uma parte [da produção], cobrindo os custos de produção, e a outra parte eles deixam para livre comercialização" (Distribuidora, entrev. 2018). Esta es la modalidad más presente en las diferentes zonas de producción de Paraguay, tanto que muchos productores no saben decir su costo en guaraní o en dólar, pero si en grano: "nesse último [ano] meu custo foi 25 sacos de soja por

${ }^{6}$ En este estudio vamos a utilizar los términos "técnicos" y "vendedores" como sinónimos, pues la misma persona ocupa ambas funciones. Ellos están vinculados a una empresa (distribuidora, exportadora, cooperativa o acopiadora) y tienen una carpeta, en general, con 20 a 25 clientes (productores rurales), para quien realizan la asistencia técnica y la comercialización de productos y servicios necesarios para la producción. 
hectare" (Entrev. 2015); "en general mi gasto para producir soja queda entre 30 y 35 bolsa por hectárea" (Entrev., 2017).

La tercera modalidad es la provisión de recursos financieros al productor, como un préstamo a ser utilizado en la producción. Aunque los productores puedan pagar en grano, es más común en efectivo. En este caso las empresas movilizan recursos financieros en los bancos y transfieren a los productores a una tasa de interés. "A empresa tem o montante do banco, que me financiou esse valor, e eu vou financiar o cliente, ou seja, é um refinanciamento" (Distribuidora, entrev. 2019). La tasa de interés cambia, tanto entre empresas como en la misma empresa. "Hoje nós oferece financiamento aos produtores, sendo $8 \%$ com hipoteca da terra e $18 \%$ sem hipoteca. Mas, claro que também depende do cliente. Mas, nossa variação fica entre 8 e 18\%" (Exportador, entrev. 2019).

Estas dos últimas modalidades son tan importantes que, de los 107 productores de soja entrevistados, comentó (el 93\%) que necesitan recursos externos a la unidad de producción del grano y el $86 \%$ mencionó que con recursos propios sería imposible cultivarlo. $Y$, entre las fuentes de estos recursos, los bancos tienen poca adherencia entre los productores de soja (13\%), mientras que las distribuidoras de insumos, cooperativas, acopiadoras y agroindustrias financian $97 \%$ de los entrevistados que dijeron que necesitan recursos externos -incluso los que recuren a los bancos, también lo hacen a través de estos actores-.

En síntesis, la relación entre los productores rurales, por un lado, y las empresas, por el otro, está permeada por una gran interdependencia. Este vínculo es estratégico para ambos, ya que es a través de él que las empresas continúan vendiendo 
insumos, proporcionando servicios y adquiriendo la producción del productor, elementos fundamentales para su funcionamiento y crecimiento. A su vez, el agricultor está interesado en la disponibilidad de recursos, en el suministro de insumos y servicios, en la garantía de venta del grano, etc. Esta situación hace que la relación sea de alto riesgo, tanto para el productor como para la empresa, ya que cualquier vínculo roto promueve graves pérdidas para ambas partes ${ }^{7}$. En este sentido, la decisión de con quién hacer negocio es de gran importancia para productores y empresas.

\section{La construcción social del mercado de la soja: los ingredientes esenciales para elegir con quién negociar}

La decisión de negociar con una u otra empresa es, para la economía neoclásica, definida por el precio, principalmente porque la soja es un producto homogéneo y de baja complejidad tecnológica. En esta interpretación, no se establecen relaciones previas entre los actores, porque hay diferentes compradores y proveedores, que son libres para elegir entre uno y otro, en función del precio (Mazzoleni y Medeiros, 2011). La nueva economía institucional, a su vez, enfatiza el papel cada vez mayor de los contratos, en que los productores deciden con quién hacer negocio en función del

\footnotetext{
${ }^{7}$ Es importante comentar que es una relación desigual de poder. Las empresas tienen mayor fuerza en estas negociaciones, sobre todo cuando los productores detienen pequeñas áreas y baja capitalización. Reconociendo esto, muchos productores construyen estrategias para expandir su autonomía, como la creación de grupos formales e informales con otros agricultores (cooperativas, asociaciones, etc.), negociación con más de una empresa simultáneamente, interiorización de ciertas actividades que tradicionalmente se realizaban fuera de la finca, entre otras (Avalos Vera y Wesz Jr., 2019).
} 
contrato que ofrece las mejores condiciones de precio, plazo, condiciones de pago, etc. (Zylbersztajn, 1995; Paes Leme y Zylbersztajn, 2008). Desde esta perspectiva, las relaciones son impersonales y funcionales, y ambos actores (empresas y productores) se guían por las mejores opciones a favor de sus propios beneficios, desprovistos de lazos comunitarios. Pero, al analizar en profundidad el mercado de la soja en Paraguay, estos argumentos presentan algunas limitaciones.

Durante la investigación de campo fue consensual entre los entrevistados que el precio de la soja es estandarizado, sin variación entre las empresas, pues se basa en la bolsa de valores de Chicago. Lo que puede variar un poco es el costo para secarla, almacenamiento, transporte al puerto y descarga en la barcaza. El gerente de una empresa exportadora (Entrev. 2019) detalla un poco más:

O preço é diretamente de Chicago. Nós não atuamos dentro do preço, quem manda o preço é a bolsa de valores, é o mercado, são os compradores que estão comprando ou não. Aí a gente negocia só o prêmio. É o custo de processamento dele [limpeza e classificação do grão], o frete para sair daqui e levar até lá no porto, isso é praticamente tabelado, e daí o prêmio porto, que é quanto que o porto te cobra para descarregar o teu soja e elevar para dentro de uma barcaça. Isso que é o prêmio. [...] Mas tudo isso varia pouco.

Este argumento estuvo presente en otras conversaciones: "o preço é tabelado e os custos são parecidos" (Cooperativa, entrev. 2019); "Para ele [produtor] não tem muita variação 
[entre o preço das empresas]. Não tem como fazer milagre!" (Exportador, entrev. 2019). Y, como la soja es un commodity (y el $100 \%$ de los encuestados cultivan variedades transgénicas, sin plantaciones convencionales u orgánicas), para la empresa es indiferente de quién comprar la soja, imposibilitando la diferenciación de la producción o cualquier iniciativa de agregación de valor.

En el sector de semillas, agroquímicos y fertilizantes también comentaron que no hay tanta variación en el precio ofrecido a los productores (con excepción de las compras en efectivo), y que "as condições dos contratos são parecidas, não muda muito, só o juro pode variar um pouco, mas é pouca coisa" (Distribuidora, entrev. 2016). Esta situación ocurre debido a la alta competencia presente en las principales regiones productoras de soja del país. "Só de empresas no ramo do agro em Alto Paraná, tem mais de 133. Tem muitas! É uma concorrência muito grande" (Distribuidora, entrev. 2018). En

Santa Rita, por ejemplo, "uns anos atrás, quando a soja tava valorizada, tinha em Santa Rita umas 80 distribuidoras. Tinha gente que trabalhava em uma distribuidora ou silo, saia e abria outra empresa" (Exportador, entrev. 2019). Actualmente, "em um raio de $50,60 \mathrm{~km}$, só de cabeça assim, sem pesquisar nada, nós levantamos 58 distribuidoras aqui na região" (Distribuidora, entrev. 2019). Esto se refleja incluso en la molestia que los productores rurales dicen sufrir con los vendedores: "tem um enxame de técnicos... se tu der muita bola para eles, só fica recebendo eles e não faz mais nada" (Productor rural, entrev. 2019). Incluso es común encontrar carteles en las entradas de la propiedad que prohíben el ingreso de técnicos sin autorización.

$Y$, en términos de formato y dinámica de negociación entre empresas y productores de soja, se escuchó que "é tudo 
igual", "a gente faz igual os concorrentes", "seguimos el mismo patrón que los demás". También se comentó que, en términos de características técnicas, los insumos son similares. Un profesor de agronomía de Santa Rita (Entrev. 2019) explicó que "el glifosato es el mismo que vende todo el mundo, hay algunas variantes de concentración de principio activo, pero todo el mundo vende el mismo [...], en categoría de producto es la misma cosa. En cuanto a los fungicidas, de forma general, cambia el principio activo y cambia la proporciones, pero no cambia muchas cosas". Y, para muchos productores rurales esto es más claro actualmente, sea porque él o sus hijos tienen alguna formación técnica, sea porque reciben mucha información simultánea vía aplicativos, programas de televisión y/o charlas técnicas. "Hoje o produtor está mais atualizado que muito representante das empresas" (Distribuidora, entrev. 2016).

Teniendo en cuenta los elementos destacados anteriormente (precio muy similar, alta competencia, formatos de negociación idénticos, condiciones contractuales equivalentes y productos similares), que neutralizan los principales argumentos de la economía neoclásica y la nueva economía institucional, cabe la pregunta: ¿qué determina que un productor rural elija una u otra compañía para comprar insumos o vender su soja? Ante esta pregunta, aparecieron un conjunto amplio de argumentos, que revelan diferentes elementos y condiciones sociales, culturales e históricas que inciden en esta elección. Como lo destaca Weber (1991), los elementos institucionales guían el comportamiento económico de los individuos, pero no lo determinan. Hay otras cuestiones que juegan un papel central en los intercambios.

En las conversaciones con técnicos y con productores rurales, la confianza, sin dudas, es algo central en el discurso 
de ambos. Esto porque ocurrieron muchas dificultades y tensiones en estas relaciones en el pasado. Del lado del productor, tenían muchos reclamos de elevado descuento en el momento de entrega del producto (con argumento de que la soja estaba muy sucia o con elevada humedad), balanza adulterada (con el menor peso, el productor recibe un valor más bajo por el grano), insumos falsificados que no alcanzaban el prometido (semillas con baja germinación, agroquímicos y abonos sin efectividad, etc.), sobrefacturación del costo de producción ("decían que era un precio, pero después era otro"), orientaciones técnicas equivocadas (indicando insumos que no eran necesarios, pero que aumentaba la comisión de los vendedores), falsificación de las firmas de los productores ${ }^{8}$ y casos de empresas que "de un día al otro cerraban la puerta y aplicaban el golpe en el productor" (Productor rural, entrev. 2018). Por parte de la empresa, "tivemos muitos clientes com que perdemos dinheiro, que sumiram no mundo e aí tivemos prejuízo" (Distribuidora, entrev. 2018). Entre las principales complicaciones relatadas aparecen: productores que entran en falencia y no tienen patrimonio para compensar sus deudas, que prefieren entregar la soja a otra firma, en vez que saldar su deuda, rompen el contrato cuando el precio de la

\footnotetext{
${ }^{8}$ Un caso que ganó mucha visibilidad involucra la distribuidora Agrícola Colonial. Según argumentan los productores, la firma hacia los préstamos, como hablamos arriba, y a cambio ellos firmaban los pagarés. Cuando llegaba la cosecha y quitaban la deuda, la empresa entregaba solo los recibos y no los pagarés. En otros casos, los productores retiraban el documento, pero después Agrícola Colonial falsificaba sus firmas en nuevos pagarés. En ambos casos, la empresa vendía los pagarés a bancos y financieras extranjeras, que empezaran a ejecutar las cobranzas. La situación aún no fue resuelta y hay aproximadamente 300 productores afectados (ABC Color, 2019).
} 
soja esta mucho más alto de lo que lo pactado, cambian de ciudad o país sin pagar sus deudas, entre otros problemas ${ }^{9}$.

Frente a este conjunto de complicaciones y molestias, la confianza se constituye en algo fundamental en la relación entre productor y empresa, según lo comentado por casi todos los entrevistados. Para la mayoría de ellos, la confianza es el primer filtro para una relación, como apunta el productor: "vamos dizer assim: vem um técnico e faz uma proposta e se for melhor que a outra, se for confiável daí também nós negociamos" (Entrev. 2020). O sea, aun con una buena propuesta de negocio - un buen precio o un buen contrato no hay negocio si no hay confianza. Aunque no era predominante, se escuchó sobre relaciones entre empresas y clientes que ocurrían sin instrumentos jurídicos formalizados:

Las negociaciones en algunos casos se realizan

sin contratos, especialmente con los productores que conoce bien y con quien

\footnotetext{
${ }^{9}$ En función de estos problemas, muchas empresas comentaban que, entre ellas, hay un cambio de información sobre los productores rurales, sea antes de hacer un negocio y así saber sobre la situación del futuro cliente ("obtener referencia"), sea cuando hay un problema y se comunica a las demás para quedar atenta a estos productores. "Toda a análise de crédito é feito dessa maneira: consulta o Informconf, Infocheck. Agora, ainda não é uma coisa totalmente informatizada que você tem acesso. Então o nosso oficial de crédito liga para o oficial da empresa A, B, C, se conversam, se falam e troca informação. É mais uma questão de cavalheiro vamos dizer assim entre as empresas" (Distribuidora, entrev. 2019); "As empresa interagem entre si para se proteger dos produtores problemáticos. Se a nós tinha enfrentado problema com um produtor que não tinha pago e tinha dado o cano, já emitíamos um comunicado pra as outras" (Distribuidora, entrev. 2018); "o gerente da Exportadora $\mathrm{X}$, é amigo da gente, o cara da distribuidora y, o cara aqui das cooperativas, eu conheço todos os diretivos. Aí não adianta, eu vou te falar uma coisa: se tem alguém quebrado, o que eu sei todas as empresas sabem" (Distribuidora, entrev. 2019). Estos relatos evidencian el papel clave de estas redes, que es una característica de lo que Fligstein (2003) llama de "formas no competitivas de competición", en que empresas protegen su posición con estrategias colaborativas.
} 
siempre se negocia (Distribuidora, entrev. 2017).

En algunos casos, con productores conocidos, se hace [negocio] directo, sin contrato, sin una garantía, pero con algunos si se realiza con garantías que ofrece el productor (Distribuidora, entrev. 2017).

Muitos negócios são feitos por telefone e depois se assina os documentos. Ele assina depois de ter o dinheiro no bolso (Exportador, entrev. 2016).

Se [o produtor] é de confiança, eu mesmo ampliava o limite de crédito dele, mas se não confio, o pedido ia para a central da empresa. [...] Tem aqueles [produtores que] você faz [negócio] de olho fechado, tem aquele que você precisa fazer algumas promessas e tem aquele que você faria questão que nem viesse na unidade (Distribuidora, entrev. 2018).

Nem sempre a gente faz contrato porque conhecemos os produtores da região. A gente faz acordos de palavra quando o cliente é sólido e confiável (Distribuidora, entrev. 2019).

Así como hay transacciones realizadas sin contratos, también ocurren casos en que no se negocia lo mismo con todo el aparato contractual formalizado. Se necesita más de un contrato para llevar a cabo la negociación, en la cual las relaciones de confianza mutua siempre son consideradas y apreciadas por ambas partes. Como dijo Weber (1991), la importancia de la norma legal (contratos) en la realización de 
transacciones económicas no debe exagerarse, ya que, a veces, tiene menos fuerza que la convención social y las normas morales. Es por esto que, para muchos, confianza es más eficaz para evitar problemas y situaciones oportunistas que la legalidad de un contrato (aunque los actores reconozcan su relevancia). Y, como comenta Almeida (2013), los "negocios de palabra" o sin una formalidad ayudan a reforzar la credibilidad de las partes involucradas.

Es importante decir que la confianza es construida procesualmente (Desconsi, 2017). Hay casos en que ella es anterior a las relaciones de negociación y otras en que es edificada intencionalmente para que pueda ocurrir el negocio. En el primer caso, está vinculado, en general, con amistades anteriores, vínculos familiares o porque negociaron por muchos años.

[No mercado da soja] tem questão de afinidade, questão de: vou ajudar um pouquinho o meu amigo ali, meu primo. Por exemplo, aqui no Paraguai é muito fácil o pessoal abrir empresa. Um vendedor nosso até estava reclamando que esse negócio é muito familiar, abrindo empresinha e [e o produtor] vai comprar porque é primo, vou ajudar meu tio (Distribuidora, entrev. 2019).

São pessoas que eu conheço, então são clientes conhecidos, que eu conheço desde que eu nasci, então são pessoas que tem um histórico. Eu tenho relação com eles desde o meu primeiro emprego. Quando eu abri minha própria empresa, meus clientes saíram 
comigo $^{10}$. Aquele cliente que se tu chega lá e o cara te recebe bem porque não é uma relação só comercial. É uma relação de confiança, não é qualquer um que chega... precisa de um tempo (Distribuidora, entrev. 2019).

En este sentido, la historicidad es un elemento importante en las negociaciones. En algunos casos, la venta de soja está inmersa en un contexto de interacción continua entre el productor y la empresa. El entrevistado de una distribuidora (Entrev. 2018) brasileña, que desde la década de 1990 actúa en Paraguay, comentó que con algunos productores, que tienen tierras en los dos países, negociaban con empresa en Brasil y cuando ella se instaló en Paraguay, siguieron la relación ahí. El gerente de una acopiadora (Entrev. 2019) comentó que "tem famílias que desde o primeiro dia que o dono da empresa pisou em Los Cedrales negociam com ele, e continua até hoje. São 40 anos, e tem caso que já está a nova geração". Son lazos construidos y mantenidos a lo largo de décadas, los cuales pudieron haber empezado en otro país o en otra generación, pero fueron mantenidos y siguen siendo alimentados a cada año.

En los casos en que la confianza es labrada para que pueda ocurrir el negocio, se trata de una estrategia, bastante común, de las empresas, dado que se reconoce que "sin confianza, no hay negocio" (Distribuidora, entrev. 2015). En esto sentido, como explicaba un técnico de un acopiadora (Entrev. 2019), él necesita tener o crear una afinidad con el productor, que puede ser por su origen, religión, equipo de fútbol, etc. Al mismo tiempo, tiene que saber las lógicas y preferencias del

${ }^{10}$ Cuando hay una elevada confianza en el técnico, ocurre con mucha frecuencia casos de clientes que lo siguen cuando este cambia de compañía. 
productor. "Pegar o perfil do cliente e trabalhar com o perfil dele... se é mais sério ou brincalhão, se é mais desconfiado, se é 'mão de vaca' ou está mais preocupado com resultado, produtividade". Incluso este tema es parte del contenido de las capacitaciones de los técnicos/vendedores. "Quando você faz um curso de venda, você começa a entender a cabeça do produtor. A nossa preparação é feita pro produtor. Como aqui nessa região tem muito técnico, naquele que eles tiverem mais afinidade é onde eles vão comprar mais" (Exportador, entrev. 2019). El relato de un agrónomo de una distribuidora (Entrev. 2019) apunta el desafío que es la construcción del vínculo y la generación de relación de confianza entre las partes.

A grande dificuldade na minha região [Itapúa] não foi eu conhecer esses clientes ou eu vender para eles, mas sim esses clientes confiarem em uma empresa que todo ano troca de profissional. Na minha área, 95\% são alemães, que vieram da Alemanha, então são pessoas mais rigorosas, mais críticas, que confia muito nas pessoas. Elas deixam bem claro que elas vão trabalhar com você, mas da forma que ela quer trabalhar e não da forma que você impõe as coisas. Então a minha maior dificuldade foi essa, desfazer algum mal-entendido ou alguma coisa que ficou para trás. Eu não comecei com 10, e sim do -10,-20. O grande diferencial é que meus pais são de origem alemã né, eu estou em uma região de origem alemã, eu entendo alemão, são coisas que já vão facilitando. [...] Nada contra, mas na minha região [de atuação] se colocar uma pessoa morena lá, vai ter uma certa 
resistência. Eu troco uma e outra palavra em alemão, a gente sabe os costumes alemães, conhece muita coisa em alemão e por isso eles são mais receptíveis.

Esta mayor confianza de los productores con técnicos que comparten una identidad cultural y lingüística, y que se encuadran dentro de los estereotipos de quien es una persona más o menos confiable, aparecieron en muchos relatos. El hecho de compartir valores, preconceptos y apellidos, o de vivir en la misma comunidad y estar insertado en las mismas redes sociales, era siempre muy bien valorado. Son elementos que se hablan directamente en algunos debates de la NSE, pues señalan el peso que las creencias y valores tienen en las elecciones de con quien negociar (Zelizer, 2003). Y, aunque se trate de una opción individual, el éxito de una relación comercial con un productor puede favorecer negocios con el conjunto de la comunidad, sobre todo en grupos más cerrados y unidos, como los menonitas. Por lo tanto, las redes sociales facilitan la circulación de información en el mercado, con las preferencias de uno transmitidas a los demás a través de estas conexiones (Granovetter, 1985).

Os mais desconfiados e que falam na lata o que pensam são os menonitas. A construção da relação de confiança é lenta, mas depois é duradoura. Se tem êxito com um menonita, é possível ter em toda a sua comunidade porque um fala para o outro. Mas um mal negócio pode gerar um rompimento com todos eles (Distribuidora, entrev. 2016). 
Na unidade lá de Campo 9 o técnico é casado com uma menonita, então ele tem muita abertura lá por esse tema, porque ele se dá muito bem lá por isso. Mesma coisa na colônia Iguaçu, que tem muito japonês. O guri que atende esses japoneses, ele é paraguaio, mas ele fala japonês. Na minha região [de atuação], lá $80 \%$ é alemão e eu falo alemão. Aí você chega com um pessoal mais de idade e começa conversar em alemão, já ganha confiança. É uma maneira de você entrar (Distribuidora, entrev. 2019).

Yo soy un agrónomo paraguayo y uno de los motivos de no trabajar con brasileños es porque estos productores tienen un poco de preconceptos sobre los profesionales paraguayos y por esto también las empresas contratan profesionales brasileños o de ese origen para atenderlos (Distribuidora, entrev. 2017).

Una vez que el técnico crea un vínculo con el productor, la preocupación es mantener esta relación a lo largo del tiempo. Más que resolver problemas agronómicos, tener precios competitivos, seguir financiando, no tener muchas burocracias, etc., es necesario estar próximo al productor. Más que una localización geográfica (que también es importante, para no ampliar mucho el costo y el tiempo de traslado), estamos hablando de una proximidad social. Es sumamente importante mantener un contacto frecuente, haciendo visitas continuas, incluso fuera del momento de producción, para hablar sobre cosas aleatorias y cotidianas. 
"Você dá uma ligada para o produtor, passa lá, toma um tereré e conversa, troca uma ideia, olha uma parcela, conversa alguma coisa e proponha que semana que vem vamos falar de negócio, hoje não" (Distribuidora, entrev. 2019). Son bien valoradas por los productores cuando ocurren estas visitas sin "hablar de negocio" y "fuera de la zafra", pues demuestra un afecto, una amistad y fortalece la confianza. Tal como dice Durkheim (1995), los actores que establecen una relación mercantil no tienen, necesariamente, contactos pasajeros que ocurren de manera superficial, precaria e inestable. Por el contrario, "los miembros están unidos por lazos que se extienden mucho más allá de los muy breves momentos en que se consuma el intercambio" (217).

Tu sabe quando que o produtor começa a confiar em você quando ele te trata pelo seu nome. Ele te conhece pelo "piá da Distribuidora X", o "cara da Distribuidora X". Quando ele fala o seu nome é porque ele sabe quem você é, você já não é mais um de empresa. Então, quando muda isso aí, o negócio começa a ficar melhor, quando ele te chama para entrar dentro de casa, quando ele te convida para um churrasco, quando tem uma série de coisas que vão sendo quebradas, quando ele te manda alguma besteira no Whatsapp, ele começa a entrar no círculo de amizade, ele tem mais confiança em você (Distribuidora, entrev. 2019).

$\mathrm{Si}$, por una parte, este relato indica diferentes momentos y situaciones en que la relación gana más confianza y está más personaliza, por otra, muestra que el límite entre amistad y negocio es muy sinuoso en este vínculo entre productores y vendedores. Para reforzar la relación, las empresas 
organizan, además de eventos técnicos (días de campo, seminarios, cursos de capacitación, etc.), actividades sociales, como pesca, bingo, fiestas de final de año o de cierre de zafra, juegos de fútbol, carta o bocha, almuerzos o cenas ("asado", "churrasco", "costelão fogo de chão", "porco no tacho", "porco no rolete", "ovelha assada"). Pero, muchas veces estas iniciativas no son para todos los clientes, solamente para los productores "mais chegados", "do dia a dia", "más amigos". Esto, incluso, genera un status entre los "invitados" y los "no invitados", que demuestra un "prestigio" entre los seleccionados y un resentimiento entre los excluidos ("organiza viagens só para os mais ricos").

El prestigio es un elemento muy importante en el mercado de soja, que puede ser visualizado cuando el productor se queda contento con la elevada presencia de técnicos en su finca, pues para él es un signo de ser un buen pagador, o cuando en la Expo Santa Rita las maquinarias mayores y más costosas tienen el nombre del productor que compró. El status, incluso, es un aspecto importante en la elección de con qué empresa negociar, siendo positivo, por ejemplo, cuando el productor tiene su foto en el Instagram de la compañía por estar entre los "mejores productores" o "con mayor productividad"; cuando "gana" un viaje (pesca en Ayolas está entre lo más recurrente) o bonos por alto rendimiento o por comprar la mayoría de los insumos en una misma revenda; o cuando el dueño de la empresa hace una visita a su casa para un café o un tereré.

Las ferias, como Expo Santa Rita y Expo Canindeyú, también son locales relevantes para fortalecer el contacto con clientes. Aunque no precisamente se firmen contratos, esto sucede con empresas y técnicos que ya tienen una relación anterior. Como comentó un productor, "nadie empieza una 
negociación con una nueva empresa en la feria" (Entrev., 2015). Trátase de un espacio para reforzar vínculos anteriores. Y es por esto que las compañías tienen sillas y mesas en sus stands y allí ofrecen a sus clientes agua, cerveza, chopp, carne, picadas, etc. Es normal ver a sus clientes sentados allí (incluso algunos jugando cartas), hablando con técnicos y gerentes sobre vida cotidiana (familia, fútbol, pesca, etc.) y negocios (fertilidad del suelo, precio, zafra futura, nueva semilla, etc.).

Otra iniciativa es participar de las actividades en las comunidades rurales y en los centros poblados. Según Almeida (2013), los vendedores son plenamente conscientes de que su conducta personal genera puntos positivos 0 negativos en sus negocios. En este sentido, consideran muy positiva su ayuda, apoyo y presencia en las festividades, donando recursos para la promoción de eventos o simplemente participando y encontrándose con los productores.

Aqui tem muitas religiões e aí cada religião faz a sua festa no domingo. Aí nós sempre coloca um pouco de dinheiro, as vezes patrocinamos a cartela, doamos papel das mesas. Assim nós estamos ajudando (Acopiadora, entrev. 2019).

Tem eventos nas cidades, nas comunidades $e$ tu acaba indo, patrocina, encontra os produtores, come um asado, toma uma cerveja com eles. É importante essa relação para manter o vínculo, a amizade (Distribuidora, entrev. 2019).

A empresa sempre ajuda em atividades beneficentes, como bingos ou almoços para 
pessoas doentes, e patrocina o time de futebol da cidade (Distribuidora, entrev. 2020).

Nosso cargo [técnico/vendedor] exige por dedicação na comunidade, ajudar em igrejas (Distribuidora, entrev. 2019).

Nas festas de comunidade sempre buscamos estar presentes, pois, "quem não é visto não é lembrado" (Distribuidora, entrev. 2019).

Otro punto que también debe ser mencionado es que existe una lógica de reciprocidad entre los productores de soja y las empresas/gerentes/técnicos (Desconsi, 2017). Muchos productores comentaron que reconocen la ayuda que obtuvieron de una empresa y que necesitan retribuir manteniendo su vínculo con ella, aunque haya otras compañías que ofrecen mejores precios o condiciones de contrato. En algunos casos, cuando compran un agroquímico de la empresa que ofrece el mejor precio, siguen adquiriendo una menor parte de la distribuidora que le "ayudó" anteriormente. Incluso si el productor rompe con la compañía, hay un resentimiento y la lógica de la reciprocidad se ve sacudida. Por ello, para algunos productores, cambiar recurrentemente de empresa es un riesgo, porque ninguna lo ayudará cuando ocurra alguna dificultad.

Cuando empecé con la soja, la empresa me ayudo en todo, desde la preparación de la tierra y todo el financiamiento que necesitaba el cultivo de soja. Fue ella la única que ayudó a los pequeños agricultores cuando no tuvieron oportunidad (Productor rural, entrev. 2017). 
Se o produtor tem confiança com duas distribuidoras, que já negocia a muito tempo, é ruim deixar um meio descontente né, porque tu já tá negociando tanto tempo (Distribuidora, entrev. 2019).

Tem produtor que reconhece que a empresa ajudou quando eu estava meio ruim das pernas. $E$ é importante esse reconhecimento, porque a empresa pode ter assumido um risco de uma dívida que as concorrentes não quiseram, caíram fora (Distribuidora, entrev. 2019).

Ele [produtor] pensa: o gerente fez isso de favor para mim, eu tenho a obrigação, eu tenho que levar duas cargas para ele. Como é que se diz, "uma mão lava a outra". Tem momentos que o preço da Empresa $N$ tá melhor que o nosso, mas em consideração eu vou levar uma ou duas cargas de soja para Empresa $V$, porque também me ajudou quando precisava (Distribuidora, entrev. 2019).

Porque nós [produtores rurais] tem que segurar um pé de meia, porque quando tu precisa de algo, de uma ajuda da empresa, se ficar pulando de galho em galho, tu nunca tem uma coisa firme. Que nem eu tava falando, uma hora nós se aperta, e ai nenhuma empresa vai me ajudar (Productor rural, entrev. 2019).

En este sentido, en el mercado local de soja existe una moralidad y una lealtad que debe cultivarse a lo largo de los años. Son negociaciones que combinan la conveniencia 
económica con la postura moral. Trátase de un conjunto de valores que están, a todo momento, siendo reforzados, legitimados y compartidos. En diferentes ocasiones los gerentes y técnicos comentaban de estos aspectos cuando identificaban a los productores "buenos de negociar" ("fiel", "forte"”, "correto", "trabalhador", "ponta firme", "de familia") contra los "malos" ("aventureiro", "enrroleiro", "malandro", "sin vergüenza", "sem palavra"). Los productores también hacían referencias a empresas "serias", "transparentes", "justas", "de credibilidad", "honestas", "acessiveis", etc. ${ }^{11}$

A pesar de la sencillez de la identificación de estas características - como señaló un gerente de una distribuidora: "se o cara é bom, é bom; se o cara é ruim, é ruim" (Entrev. 2018) - es mucho más complejo. Estas reputaciones están asociadas, sobre todo, a las definiciones construidas localmente, donde algunos elementos realzan la etiqueta de "bueno", como el hecho de ser fiel a los plazos y compromisos, no cambiar de empresa con frecuencia, ser de una familia conocida, participar de los eventos locales, no hacer inversiones innecesarias (como cambiar de automóvil antes de pagar a los acreedores), no estar involucrado en problemas comunitarios, no tener adicción, etc. Estas son percepciones, valores, calificaciones y reputaciones que tienen muchos efectos, incluso se reflejarán en las elecciones de con quien establecer relaciones comerciales. Como ya decía Weber (1991) y fue reiterado por autores de la NSE

\footnotetext{
${ }^{11}$ Aunque los actores locales comparten estos valores, sus relaciones con una empresa o su histórico puede crear visiones totalmente diferentes sobre ella. Un caso llamo atención porque la misma compañía era vista por algunos como "responsable", "buena de negociar", "seria", y por otros como una empresa sin escrúpulos porque "tomou a terra de vários pequenos agricultores". Aunque estaba en el contrato que, si el productor no saldaba la deuda, la empresa se queda con la tierra hipotecada, para muchos productores es una conducta moralmente equivocada.
}

Estudios Paraguayos - Vol. XXXIX, № 1 - Junio 2021 www.estudiosparaguayos.org 
(Wanderley, 2002; Marques, 2003, Steiner, 2006), el comportamiento económico, en su conjunto, está completamente sujeto a códigos y valores morales, ya que las transacciones de mercado no son independientes del entorno social.

Al aproximar los resultados discutidos hasta ahora con los debates de la NSC, especialmente con el marco propuesto por Beckert (2009 y 2010), se puede decir que el mercado de la soja, especialmente la relación entre productores y empresas, es construido por instituciones, redes sociales y esquemas cognitivos. Dentro del ámbito institucional, como ya se detalló, en el mercado las reglas se materializan en los contratos, que se utilizan ampliamente porque ofrecen cierta seguridad jurídica entre las partes. Sin embargo, los elementos institucionales no se limitan a la legalidad, ya que, como fue posible ver, hay acuerdos verbales que siguen siendo efectuados entre productores y empresas.

Las redes sociales también son fundamentales en la materialización de los negocios. Incluso cuando la empresa es nueva en la región, contrata personas que trabajan allí (sobre todo de una concurrente) para traer el cliente a la empresa, ya que son gerentes o técnicos que conocen al público local y que también son reconocidos por ellos. $\mathrm{Y}$, como el mercado de la soja se basa en estructuras de interacción regulares, es clave la confianza, la reciprocidad, la trayectoria de relación, los lazos familiares, la amistad, la lealtad y el compromiso mutuo, incluso porque en estos distritos "todos conocen a todos".

El marco cognitivo aparece en los valores y en la reputación social intrínseca de las relaciones económicas. Fue interesante notar el peso de los repertorios culturales en las negociaciones, y cómo las compañías toman esto en cuenta, 
asignando a ciertas regiones vendedores que comparten la cultura local o que tienen alguna conexión con la comunidad. Entre los elementos simbólicos, se puede destacar el status, pues tiene su prestigio estar entre los seleccionados para el asado o entre los productores que tienen su foto en el Instragram de la empresa. La selección de productores "buenos" también evidencia una serie de valores y calificaciones sociales, que no están en las reglas y normativas de la compañía, pero influye en las decisiones y estrategias de técnicos y gerentes.

En resumen, este conjunto variado de elementos y dinámicas que definen y mantienen las relaciones de intercambio comercial entre productores y empresas apunta a la complejidad y multidimensionalidad de la construcción social del mercado de la soja en Paraguay. Como comentó un técnico de una distribuidora (Entrev. 2019), "hoje em dia você tem que ter preço, você tem que estar olhando lavoura, tem que estar fazendo social, tem que estar ajudando em festa da comunidade, tem que estar dando brindes, tem que ser agrônomo, assistente social, psicólogo". Esta mezcla de ingredientes demuestra que, en las relaciones comerciales, los límites entre la economía y la sociedad son imperceptibles, como es el vínculo entre la amistad y el negocio. Estos resultados demuestran que no se trata de intercambios anónimos y desconectados, sino de transacciones económicas mantenidas por elementos sociales, culturales e históricos territorializados. 


\section{Consideraciones finales}

Este estudio apunta a que, a pesar de que la producción de la soja sea una actividad estandarizada, con precio internacional, pautado en un comercio global y con importante actuación de grandes productores y empresas transnacionales, su mercado está profundamente vinculado con las dinámicas socioculturales de las comunidades donde están insertados los productores rurales y las empresas. Aunque el precio del producto y las condiciones del contrato sean factores importantes de la transacción mercantil, en general no son los elementos que determinan este vínculo, que involucra relaciones de confianza, amistad, familia, historial de relacionamiento, reciprocidad, compromiso moral, status, reputaciones, etc.

En este sentido, el análisis de la construcción social del mercado, a partir de la NSE, confirma que la negociación entre productores y empresas no está ajena a las relaciones sociales, valores culturales y marcos institucionales. Al revés, estos elementos son de central importancia para evitar problemas, dificultades y tensiones que puedan ocurrir entre agricultores y compañías. Ambos actores reconocen que, además de un contrato, los aspectos sociales, culturales e históricos son necesarios para combatir prácticas oportunistas en las transacciones económicas. En vez del mercado como una esfera independiente, soberana e instrumental con individuos que no tienen ningún tipo de relación permanente entre sí, lo que vimos fueron acciones económicas construidas y alimentadas continuamente entre personas que se conocen, cooperan y disputan posiciones, cuyas prácticas y decisiones tienen fuerte arraigo en la vida social y comunitaria en que están insertos. 
Por fin, nos parece importante, por un lado, profundizar los resultados alcanzados en este trabajo, analizando con más detalle los diferentes elementos presentados, así como abordar con mayor atención las tensiones en estas negociaciones y las relaciones colaborativas dentro de cada grupo (productores y empresas). Por otro lado, es necesario expandir los estudios con este énfasis teórico metodológico, poniendo en evidencia las ciencias sociales - no solo la NSE - en la interpretación de los fenómenos económicos. Son necesarios referenciales teóricos que capten la complejidad de la dinámica existente entre sociedad y economía.

\section{Agradecimiento}

Agradezco a la Universidad Federal de Integración 143 Latinoamericana (UNILA) por el Programa de Apoyo a Investigadores (No. 109/2017/PRPPG y No. 80/2019/PRPPG) y estudiantes de iniciación científica de diferentes años (Gabriel Avalos Vera, Raimundo Christian Oliveira Soares, Maria Victoria Garayo Mereles, Wellington Luciano dos Santos, Caroline Bosio Grappegia, Jorge Morel); al Grupo de Estudio en Cambio Social, Agronegocios y Políticas Públicas (GEMAP/CPDA/UFRRJ), con énfasis al proyecto de investigación "Expansión del 'agronegocio', mercado y extranjerización de tierras y acción del Estado: una mirada crítica a las transformaciones en el medio rural brasileño", que cuenta con el apoyo de FAPERJ y CNPq, coordinado por el prof. Sergio Pereira Leite. 


\section{Referencias}

- $\mathrm{ABC}$ Color. 2019. Posible estafa masiva a productores del Este. Recuperado de: https://www.abc.com.py/edicionimpresa/economia/2019/12/04/posible-estafa-masiva-aproductores-del-este/

- Abramovay, R. 2009. "Anticapitalismo e Inserção Social dos Mercados". Revista Tempo Social - Revista de Sociologia da USP, Vol. 21, No. 1, pp. 65-87.

- Almeida, L. S. 2013. "Gaúchos, Festas e Negócios: O Agronegócio da Soja no Meio-Norte Mato-Grossense". Tesis (Doctorado en Sociología y Antropología), Universidad Federal de Rio de Janeiro, Rio de Janeiro.

- Aprosemp - Asociación de Productores de Semillas de Paraguay. 2019. "Estadísticas". Recuperado de: http://www.aprosemp.org.py/stadistics

- Beckert, J. 2009. "El Orden Social de los Mercados". Comunicación, Cultura y Política, Vol. 1, No 2, pp. 147-172.

- Beckert, J. 2010. "How Do Fields Change? The Interrelations of Institutions, Networks and Cognition in the Dynamics of Markets". Organization Studies, Vol. 31, No. 5, pp. 605-627.

- Bourdieu, P. 2001. "As Estruturas Sociais da Economia". Lisboa: Instituto Piaget.

- $\quad$ Busch, L.; Tanaka, K. 1996. "Rites of passage: constructing quality in a commodity subsector". Science, Technology \& Human Values, Vol. 21, No, 1, pp. 3-27.

- Cadam - Cámara de Distribuidores de Automotores y Maquinarias. 2019. "Estadísticas". Recuperado de: https://www.cadam.com.py/statistics

- Capeco - Cámara Paraguaya de Exportadores y Comercializadores de Cereales y Oleaginosas. 2019. "Estadísticas". Recuperado de: http://capeco.org.py

- Cargill Paraguay. 2020. "Localidades". Recuperado de: https://www.cargill.com.py/es/localidades

- Desconsi, C. 2017. "O controle da lavoura: a construção de relações sociais e a produção de soja entre assentados do 
meio norte de Mato Grosso". Tesis (Doctorado en Sociología y Antropología), Universidad Federal de Rio de Janeiro, Rio de Janeiro.

- DNA - Dirección Nacional de Aduanas. 2020. "Informes Estadísticos". Recuperado de: https://www.aduana.gov.py/105-1-informes-

estadisticos.html

- Durkheim, E. 1995. "Da Divisão do Trabalho Social". São Paulo, Martins Fontes.

- Fligstein, N. 2003. "O Mercado enquanto Política: Uma Abordagem Político-Cultural às Instituições do Mercado", en R. Marques e J. Peixoto (orgs.), A Nova Sociologia Econômica: Uma Antologia. Oeiras, Celta Editora, pp. 195227.

- Fligstein, N. 2001. "The Architecture of Markets: An Economic Sociology of $21^{\text {st }}$ Century Capitalist Societies". Princeton, Princeton University Press.

- Galeano, L. A. 2012. "El caso del Paraguay" en FAO (Org.). Dinámicas del mercado de la tierra en América Latina y el Caribe: concentración y extranjerización. Roma: FAO, pp. 407-434.

- Granovetter, M. 1985. "Economic Action and Social Structure: The Problem of Embeddedness". American Journal of Sociology, Vol. 91, No 3, pp. 481-510.

- Heredia, B. M. A.; Palmeira, M.; Leite, S. P. 2010. "Sociedade e Economia do Agronegócio". Revista Brasileira de Ciências Sociais, Vol. 25, pp. 159-176.

- MAG - Ministerio de Agricultura e Ganadería. 2009. "Censo Agropecuario de 2008". Asunción: MAG.

- MAG - Ministerio de Agricultura e Ganadería. 2020. "Series Históricas de Cultivos Temporales". Recuperado de: http://www.mag.gov.py

- Marques, R. 2003. "Introdução: Os Trilhos da Nova Sociologia Econômica”, en R. Marques e J. Peixoto (orgs.), A Nova Sociologia Económica: Uma Antologia. Oeiras, Celta Editora, pp. 1-67. 
- Mazzoleni, E. M.; Medeiros, J. J. 2011. "Governança e Coordenação em Cadeias de Suprimento: Proposta de um Modelo Tecnológico-Relacional para Análise no Agronegócio", en XLIX Congresso da SOBER, Belo Horizonte.

- Murphy, S.; Burch, D.; Clapp, J. 2012. "Cereal secrets: the world's largest grain traders and global agriculture". Oxford: Oxfam.

- Paes Leme, M. F.; Zylbersztajn, D. 2008. "Determinantes da Escolha de Arranjos Institucionais: Evidências na Comercialização de Fertilizantes para Soja". Revista de Economia e Sociologia Rural, Vol. 46, No. 2, pp. 517-546.

- Polanyi, K. 1980. "A grande transformação: as origens da nossa época". Rio de Janeiro: Campus.

- Raud-Mattedi, C. 2005. "A construção social do mercado em Durkheim e Weber". Revista Brasileira de Ciências Sociais, Vol. 20, No. 57, pp. 127-142.

- Rojas Villagra, L. 2009. "Actores del agronegocio en Paraguay". Asunción: Basels.

- Steiner, P. 2006. "A Sociologia Econômica". São Paulo, Atlas.

- Vera, G. A.; Wesz Jr., V. J. 2019. "Las estrategias de los productores de soja en la negociación con las empresas en el Noreste del Departamento de San Pedro (Paraguay)". Revista Espaço Acadêmico, Vol. 18, No. 212, pp. 126-140.

- Wanderley, F. 2002. "Avanços e Desafios da Nova Sociologia Econômica: Notas sobre os Estudos Sociológicos do Mercado". Sociedade e Estado, Vol. 17, No. 1, pp. 15-38.

- Weber, M. 1991. "Economia e Sociedade". Brasília, Editora da UnB.

- Wesz Jr., V. J. 2014. "O mercado da soja e as relações de troca entre produtores rurais e empresas no sudeste de Mato Grosso (Brasil)". Tesis (Doctorado en Ciencias Sociales en Desarrollo, Agricultora y Sociedad), 
Universidad Federal Rural de Rio de Janeiro, Rio de Janeiro.

- Wesz Jr., V. J. 2016. "Strategies and hybrid dynamics of soy transnational companies in the Southern Cone". Journal of Peasant Studies, Vol. 43, No. 2, pp. 286-312.

- Wesz Jr., V. J. 2018. "O mercado da soja no Paraguai: concentração e transnacionalização". Revista PAMPA, Vol. 18, pp. 99-123.

- Wesz Jr., V. J. 2019. "O mercado da soja no sudeste de Mato Grosso (Brasil): uma análise das relações entre produtores rurais e empresas a partir da sociologia econômica". Dados, Vol. 62, No. 1, pp. 1-36.

- Wesz Jr., V. J. 2021. "Soybean production in Paraguay: agribusiness, economic change and agrarian transformations". Journal of Agrarian Change, pp. 1-24.

- Wilkinson, J. 2008. "Mercados, redes e valores". Porto Alegre, UFRGS.

- Wilkinson, J. 2011. "From fair trade to responsible soy: social movements and the qualification of agrofood markets". Environment and Planning, Vol. 43, No. 9, pp. 2012-2026.

- Zelizer, V. 2003. "O significado Social do Dinheiro", en R. Marques e P. Peixoto (orgs.), A Nova Sociologia Económica: Uma Antologia. Oeiras, Celta Editora, pp. 195227.

- Zylbersztajn, D. 1995. "Estruturas de governança e coordenação do agribusiness: uma aplicação da nova economia das instituições". Tesis de Livre-Docência, Universidad de São Paulo, São Paulo. 